\title{
1,10-Phenanthroline Modulated Redox Potentials Explored for Benign Iron Speciation Analysis
}

\author{
Masood Ahmad Rizvi, ${ }^{a}$ Norio Teshima, ${ }^{b, *}$ and Ghulam Mustafa Peerzada ${ }^{a}$ \\ ${ }^{a}$ Department of Chemistry, University of Kashmir, Srinagar, 190006, J\&K, India \\ ${ }^{\mathrm{b}}$ Department of Applied Chemistry, Aichi Institute of Technology, 1247 Yachigusa, Yakusa-cho, Toyota 470-0392, Japan
}

RECEIVED AUGUST 23, 2012; REVISED AUGUST 7, 2013; ACCEPTED AUGUST 26, 2013

\begin{abstract}
The objective of this study is to develop a simple, environmentally benign alternate analytical method for simultaneous estimation of iron oxidation states. This proposed method of iron speciation is based on 1,10-phenanthroline (phen) modified redox potential of transition metal ions. In a pre-step excess cerium(IV) oxidizes iron(II) in sample to iron(III). Initial back titration of un-reacted cerium(IV) with cobalt(II) in presence of phen gives amount of iron(II) in sample, reduction of iron(III) with cobalt(II) is then used to estimate total iron as iron(III). The potentiometric titration method has been successfully tested for determinations of iron(II) and total iron in synthetic and natural samples and represents a distinctively green alternative to other reported protocols of iron speciation analysis. (doi: 10.5562/cca2167)
\end{abstract}

Keywords: ligand effect on redox potential, 1,10-phenanthroline, iron speciation, green analytical chemistry, potentiometric titration

\section{INTRODUCTION}

Iron is one of the most common and important bioactive trace metal in water systems. The biogeochemistry of iron in natural water is a function of its oxidation state, extent of hydrolysis and degree of complexation with different inorganic and organic ligands existing in the water environment. Dissolved iron generally exists in two oxidation states iron(III) and iron(II), of which iron(III) is the thermodynamically more stable form in oxygenated waters. There are several processes, however, that reduce iron(III), leading to measurable concentrations of iron(II) in surface water. The chemical speciation $^{1,2}$ and simultaneous determination ${ }^{3}$ of the two iron oxidation states is increasingly needed in areas such as bio/clinical chemistry, environmental chemistry and other scientific and industrial fields. ${ }^{4-7}$ This stimulates progress in developing analytical methods and instrumentation applied to the determination and speciation of iron. ${ }^{8}$ Although good analytical methods of metal ion estimation like atomic absorption spectrometry (AAS), inductively coupled plasma atomic emission spectrometry (ICP-AES) and $\mathrm{X}$ ray fluorescent spectrometry (XRF) detect metal ions at $\mathrm{mg} \mathrm{L}^{-1}$ (ppm) and even lower concentrations, they cannot distinguish any difference in the metal oxidation states and as such are inappropriate for iron speciation. Many alternate methods ${ }^{9-13}$ have been reported in literature for simultaneous determination of iron(II) and iron(III) in different samples. However, sampling, sample handling, pre-concentration and/or separation of the speciated forms requires rigorous procedures with sophisticated instrumentation inaccessible to common labs. Thus environmentally benign analytical methods with high versatility, selectivity, sensitivity, precision, and reproducibility are still desired. ${ }^{14}$ In continuation of our work on complexation effect of redox potential ${ }^{15}$ and its utilization in novel analytical monitoring of transition metal ion mixtures, ${ }^{16,17}$ we recently described potentiometric estimation of iron oxidation states through coordination inspired redox behavior of cobalt and iron species. ${ }^{18}$ This article describes green electrochemistry and extends the work to environment friendly method for simultaneous speciation of iron(II) and iron(III). The method is based on the redox reaction of cerium(IV) and iron(II) to produce iron(III), then back titration of cerium(IV) with cobalt(II) for estimation of iron(II) and further titration of iron(III) with cobalt(II) to give total iron concentration, under the redox potential modification with 1,10 phenanthroline ligand. This method is robust, less-toxic, atom economical and single step potentiometric alternative of simultaneous estimation of iron oxidation states. Moreover solidification of reaction waste allows safe disposal preventing risk of human exposure and damage

\footnotetext{
* Author to whom correspondence should be addressed. (E-mail: teshima@aitech.ac.jp)
} 
to water bodies. The method was applied for determinations of iron(II) and total iron in lab made (synthetic) and in natural water samples (Dal lake) standard iron ores, rock samples and also commercially available pharmaceutical samples with results in good agreement to a standard spectrophotometric method. This article represents the application of the 1,10-phenanthroline ligand modulated redox potential and its utilization in the concept of green electro analytical chemistry.

\section{EXPERIMENTAL}

\section{Apparatus}

Potentiometric titrations were performed manually using a commercially available platinum indicator and calomel reference electrode over a potentiometer (Systronics India Model 318) at $T=50{ }^{\circ} \mathrm{C} \pm 2{ }^{\circ} \mathrm{C}$. pH was measured using a Labindia $\mathrm{pH}$ analyzer (PHAN) fitted with Lp-01 pH electrode. A Siskin Julabo thermostat was used to maintain a constant temperature within $\pm 2{ }^{\circ} \mathrm{C}$. The titration vessel consisted of a specially designed six necked vessel (one each for micro burette, platinum, calomel electrodes, temperature probe, inlet and outlet of nitrogen gas).

\section{Reagents and Solutions}

All solutions were prepared with nitrogen purged, double distilled, millipore water using analytical grade chemicals from Merck India. A cerium(IV) and cobalt(II) solution $2 \times 10^{-2} \mathrm{~mol} \mathrm{~L}^{-1}$ each were prepared from ammonium cerium(IV) sulphate dihydrate $(1.2652 \mathrm{~g}$ in $100 \mathrm{~mL}$ of 1.0 mol L ${ }^{-1}$ sulphuric acid) and cobalt(II) chloride hexahydrate $(0.4760 \mathrm{~g}$ in $100 \mathrm{~mL}$ of distilled water). An iron(II) and iron(III) solution $1 \times 10^{-2} \mathrm{~mol} \mathrm{~L}^{-1}$ each were prepared using ammonium iron(II) sulphate hexahydrate and ammonium iron(III) sulphate dodecahydrate $(0.3992 \mathrm{~g}$ and $0.4822 \mathrm{~g}$ in $100 \mathrm{~mL}$ of $1.0 \mathrm{~mol} \mathrm{~L}{ }^{-1}$ sulphuric acid respectively). A phen solution $2 \times 10^{-1} \mathrm{~mol} \mathrm{~L}^{-1}$ was prepared from 1,10-phenanthroline monohydrate $(3.9648 \mathrm{~g}$ in $100 \mathrm{~mL}$ of distilled water prior acidified with $10 \mathrm{~mL}$ of $1.0 \mathrm{~mol} \mathrm{~L}^{-1}$ sulphuric acid).

\section{Procedure}

All titrations were performed at $50{ }^{\circ} \mathrm{C}$ under nitrogen atmosphere over a magnetic stirrer. The samples were titrated with $2 \times 10^{-2} \mathrm{~mol} \mathrm{~L}^{-1}$ cobalt (II) solution added in increments of $0.1 \mathrm{~mL}$ throughout titration. The EMF values were recorded when change was within $\pm 2 \mathrm{mV}$. The analytical details of the three volumetric flasks A, B and $\mathrm{C}$ used in experiment are summarized in Table 1. After an initial development time of 10 minutes, $25 \mathrm{~mL}$ aliquot from each flask were taken and raised to a temperature of $50{ }^{\circ} \mathrm{C}$ before titration.

\section{RESULTS AND DISCUSSION}

The set of chemical reactions describing different stages of experiment can be shown as

Before start of titration:

$$
\left[\mathrm{Fe}(\text { phen })_{3}\right]^{2+}+\left[\mathrm{Ce}\left(\mathrm{OH}_{2}\right)_{6}\right]^{4+} \rightarrow\left[\mathrm{Fe}(\text { phen })_{3}\right]^{3+}+\left[\mathrm{Ce}\left(\mathrm{OH}_{2}\right)_{6}\right]^{3+}
$$

Up to first equivalence point:

$$
\left[\mathrm{Ce}\left(\mathrm{OH}_{2}\right)_{6}\right]^{4+}+\left[\mathrm{Co}(\text { phen })_{3}\right]^{2+} \rightarrow\left[\mathrm{Ce}\left(\mathrm{OH}_{2}\right)_{6}\right]^{3+}+\left[\mathrm{Co}(\text { phen })_{3}\right]^{3+}
$$

Between first and second equivalence point:

$$
\left[\mathrm{Fe}(\text { phen })_{3}\right]^{3+}+\left[\mathrm{Co}(\text { phen })_{3}\right]^{2+} \rightarrow\left[\mathrm{Fe}(\text { phen })_{3}\right]^{2+}+\left[\mathrm{Co}(\text { phen })_{3}\right]^{3+}
$$

The phen modulated redox potentials of cobalt (II) and iron(II) allow the reduction of both cerium(IV) and iron(III) by the cobalt(II) without any interference. ${ }^{19}$ The concept was explored for utilization in simultaneous estimation of iron oxidation states in an environmentally benign and simple potentiometric alternative. This method involves redox back titration using standardized cerium(IV) as excess reagent, which oxidizes iron(II) to iron(III) in a pre-step to titration (reaction1). The titrant in the form of cobalt(II) phen complex first reduces the un-reacted cerium(IV) to cerium(III) (reaction 2) and then total iron(III) to iron (II) (reaction 3). The plot of EMF and volume of cobalt (II) in the presence of phen displayed two clear inflection points as shown in Figure 1.

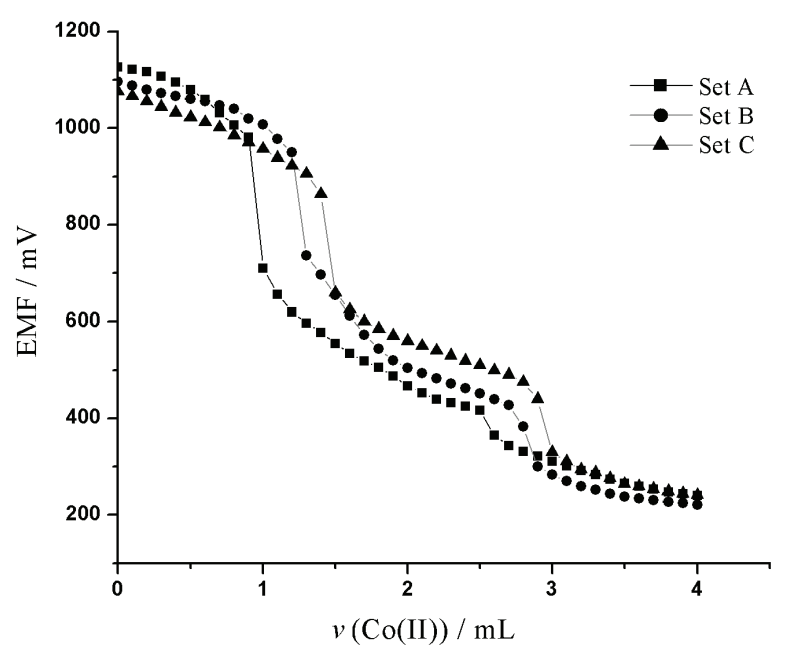

Figure 1. Potentiometric iron speciation analysis in three sets of lab made synthetic samples with different iron(II) and iron(III) concentrations; $c(\mathrm{Co}(\mathrm{II}))=2 \times 10^{-2} \mathrm{~mol} \mathrm{dm}^{-3}$. 
Table 1. Experimental data for iron speciation in synthetic samples

\begin{tabular}{|c|c|c|c|c|}
\hline Species & $\begin{array}{l}\text { Concentration / } \\
\text { mol L }^{-1}\end{array}$ & $\begin{array}{c}\text { Flask A / } \\
\mathrm{mL}\end{array}$ & $\begin{array}{c}\text { Flask B / } \\
\mathrm{mL}\end{array}$ & $\begin{array}{c}\text { Flask C / } \\
\mathrm{mL}\end{array}$ \\
\hline Iron(II) & $1 \times 10^{-2}$ & 4.0 & 3.0 & 2.0 \\
\hline Iron(III) & $1 \times 10^{-2}$ & 2.0 & 3.0 & 4.0 \\
\hline Cerium(IV) & $2 \times 10^{-2}$ & 4.0 & 4.0 & 4.0 \\
\hline 1,10-phenanthroline & $2 \times 10^{-1}$ & 10.0 & 10.0 & 10.0 \\
\hline Sulphuric acid & $1 \times 10^{-1}$ & 30.0 & 30.0 & 30.0 \\
\hline Total & - & 50.0 & 50.0 & 50.0 \\
\hline $\begin{array}{l}\text { Cobalt(II) consumed for } 1^{\text {st }} \\
\text { potentiometric equivalence }\end{array}$ & $2 \times 10^{-2}$ & 1.0 & 1.3 & 1.5 \\
\hline $\begin{array}{l}\text { Cobalt(II) consumed for } 2^{\text {nd }} \\
\text { potentiometric equivalence }\end{array}$ & $2 \times 10^{-2}$ & 2.6 & 2.8 & 3.0 \\
\hline
\end{tabular}

Titration conditions and calculations of Figure1:

Set A: Fe(II), $v=25 \mathrm{~mL}, c=8 \times 10^{-4} \mathrm{~mol} \mathrm{~L}^{-1} ; \mathrm{Fe}(\mathrm{III}), v=25 \mathrm{~mL}, c=4 \times 10^{-4} \mathrm{~mol} \mathrm{~L}^{-1}$.

Set B: Fe(II), $v=25 \mathrm{~mL}, c=6 \times 10^{-4} \mathrm{~mol} \mathrm{~L}^{-1} ; \mathrm{Fe}(\mathrm{III}), v=25 \mathrm{~mL}, c=6 \times 10^{-4} \mathrm{~mol} \mathrm{~L}^{-1}$.

Set C: Fe(II), $v=25 \mathrm{~mL}, c=4 \times 10^{-4} \mathrm{~mol} \mathrm{~L}^{-1} ; \mathrm{Fe}(\mathrm{III}), v=25 \mathrm{~mL}, c=8 \times 10^{-4} \mathrm{~mol} \mathrm{~L}^{-1}$.

Titration conditions: $\mathrm{Ce}(\mathrm{IV}), v=25 \mathrm{~mL}, c=1.6 \times 10^{-3} \mathrm{~mol} \mathrm{~L}^{-1} ; \mathrm{Co}(\mathrm{II}), c=2 \times 10^{-2} \mathrm{~mol} \mathrm{~L}^{-1} ; \mathrm{pH}=1.29 ; T=50^{\circ} \mathrm{C} ; \mathrm{L} / \mathrm{M}$ ratio $=12.5$ (ratio of amount of phen and total amount of metal ions i.e. 2: $0.16=0.04$ iron(II) +0.04 iron(III) +0.08 Cerium(IV)).

The first endpoint corresponds to the excess (unreacted) amount of cerium(IV) subtracting the excess amount of cerium from amount of cerium initially added gives the amount of cerium(IV) consumed which is equal to amount of iron(II) present in the sample and the second inflection point corresponded to the equivalence of iron(III) (total iron). From the first equivalence point the amount of iron(II) in the mixture is determined and from second inflection point the amount of initial iron(III) in the mixture is determined by subtracting the amount of iron(II) obtained from first endpoint. The analytical figures of merit in this method include: a fairly low detection limit of $0.5 \mathrm{mmol} \mathrm{L}^{-1}$ for iron(II) and $1.0 \mathrm{mmol} \mathrm{L}^{-1}$ for iron(III), a wide dynamic range of $5 \times 10^{-4}-5 \times 10^{-1} \mathrm{~mol} \mathrm{~L}^{-1}$ for iron(II) and $1 \times 10^{-3}-$ $5 \times 10^{-1} \mathrm{~mol} \mathrm{~L}^{-1}$ for iron(III).

\section{Ligand Modified Redox Potential}

The underlying concept of phen modulated redox potentials is shown in Figure 2. The theoretical analysis of phen metal complexes reveals a charge transfer absorption band involving $\pi$ electron migration from the $\mathrm{d} \pi\left(t_{2 g}\right.$ type) orbitals of metal (HOMO) to the lowest vacant $\pi^{*}$ molecular orbital of the phen ligand (LUMO). ${ }^{20,21}$

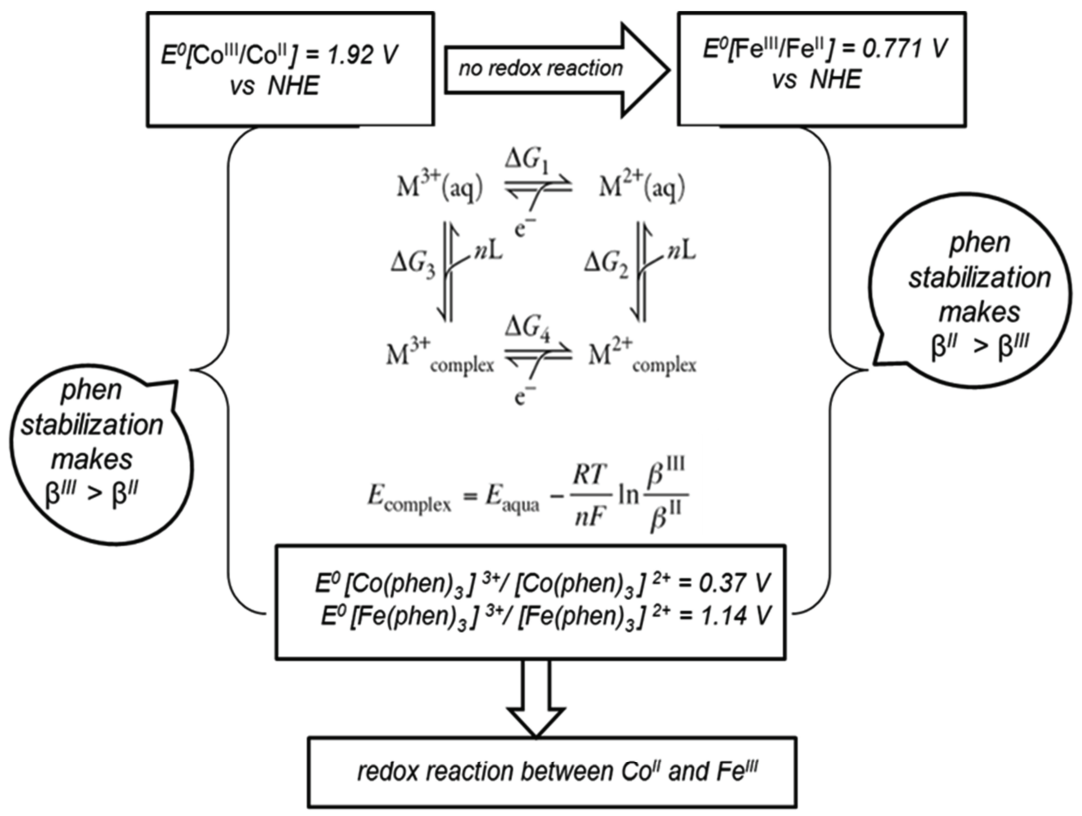

Figure 2. Schematic representation of 1,10-phenanthroline(phen) modified electrochemical behavior. 
This electron migration between metal HOMO and ligand LUMO is considered to be of stabilizing nature as is evident from the higher formation constant of iron(II) phen complex $\left(\log \beta_{3}=21.3\right)$ over iron(III) phen complex $\left(\log \beta_{3}=14.1\right){ }^{22}$ The shifts in the redox potentials of iron(II) complexes with electron withdrawing substituent on phen ligand also validate this point. ${ }^{23,24}$ The most desirable condition for this electron transfer is diamagnetic, low spin $t_{2 g}^{6}$ configuration of the metal centre. Octahedral phen complexes of iron(II) and cobalt(III) with $t_{2 g}^{6}$ configuration allow maximum electron transfer from metal HOMO to ligand LUMO and hence are more stabilized relative to iron(III) and cobalt(II) phen complexes. The HOMO-LUMO $\pi$ electron transfer in iron(III) and cobalt(II) phen complexes is less favored due to higher charge density and $t_{2 g}^{5}$ configuration in case of iron(III) and $t_{2 g}^{6} e_{g}^{1}$ configuration in case of cobalt(II). ${ }^{16}$ The correlation between metal(III), metal(II) complex stabilities and resultant formal redox potential can be obtained using equation ${ }^{15}$

$$
E_{\text {complex }} / \mathrm{mV}=E_{\text {aqua }} / \mathrm{mV}-(59.16 \mathrm{mV}) \log \frac{\beta^{\text {III }}}{\beta^{\text {II }}}
$$

where $E_{\text {complex }}$ represents the formal potential of the metal phen complex, $E_{\text {aqua }}$ represents the formal potential of $\left[\mathrm{M}\left(\mathrm{OH}_{2}\right)_{6}\right]^{3+} /\left[\mathrm{M}\left(\mathrm{OH}_{2}\right)_{6}\right]^{2+}$ redox couple. $\beta^{\mathrm{III}}$ and $\beta^{\mathrm{II}}$ are the overall thermodynamic stability constants for the metal(III) and metal(II) phen complexes respectively. The value $59.16 \mathrm{mV}$ is for $25{ }^{\circ} \mathrm{C}$. As can be seen from the Eq. (4), complexes which favor stabilization of bound metal in the $3+$ oxidation state will lower the formal redox potential than that of aqueous form, while complexes which stabilize the bound metal in $2+$ oxidation state will raise the reduction potential from that of the aqueous form. Since phen ligand stabilizes low spin $\mathrm{d}^{6}$ systems with $t_{2 g}^{6}$ configuration, it stabilizes iron(II) more than iron(III) and cobalt(III) more than cobalt(II). This lowers formal redox potential of $\mathrm{Co}(\mathrm{III}) / \mathrm{Co}$ (II) phen complex $\left(E^{\circ}\left[\mathrm{Co}(\text { phen })_{3}\right]^{3+} /\left[\mathrm{Co}(\text { phen })_{3}\right]^{2+}=0.37 \mathrm{~V}\right)$ and raises the formal potential of iron(III)/iron(II) phencomplex. $\left(E^{\circ}\left[\mathrm{Fe}(\text { phen })_{3}\right]^{3+} /\left[\mathrm{Fe}(\text { phen })_{3}\right]^{2+}=1.14 \mathrm{~V}\right)^{19}$ relative to their free (aqua) state potentials.

Factors which influence complexation of phen with cobalt and iron whether, in the form of protonation of ligand at very low $\mathrm{pH}$ or complex stability at higher $\mathrm{pH}$ or inappropriate ligand amounts have an influence on iron speciation by this method. The proposed method was optimized for $\mathrm{pH}$, temperature and phen concentration while no potential jump was observed in absence of phen, two clear inflections at corresponding equivalence points were observed at $\mathrm{L} / \mathrm{M}$ ratio higher than 10 . The potential change at the equivalence point increased with increase in the concentration of phen ligand, Eq. (5) ${ }^{25}$ It was observed that phen to total metal mole ratio of 12 or higher is optimum for iron speciation analysis by this method.

$$
E_{\text {complex }}=E_{\text {aqua }}^{\circ}+\frac{2.303 R T}{n F} \log \beta+\frac{2.303 R T}{n F} \log \left[\mathrm{ML}_{n}\right]^{n+}
$$

where $\left[\mathrm{ML}_{n}\right]^{n+}$ and $\beta$ represent the concentration and staility of metal phenanthroline complex.

The temperature effect on titration was studied at the two different $\mathrm{L} / \mathrm{M}$ ratios (9.5 and 12.5). In the lower $\mathrm{L} / \mathrm{M}$ ratio (9.5) prominent potential breaks were not obtained below $50{ }^{\circ} \mathrm{C}$. However the temperature requirement for prominent potential breaks was curtailed to $40{ }^{\circ} \mathrm{C}$ at higher $\mathrm{L} / \mathrm{M}$ ratio. This was ascribed to poor phen complexation at lower $\mathrm{L} / \mathrm{M}$ ratio hence requiring higher temperature for effective reaction. The temperature influence of reaction predicts a kinetic barrier, in the form of high activation energy required for outer sphere electron transfer process, (reorganization energy of solvent molecules, matching of metal ligand bond lengths in the two complexes). The energy of activation may be expressed as the sum of three terms: ${ }^{26}$

$$
\Delta G^{\ddagger}=\Delta G_{\mathrm{t}}^{\ddagger}+\Delta G_{\mathrm{i}}^{\ddagger}+\Delta G_{\mathrm{o}}^{\ddagger}
$$

where $\Delta G_{\mathrm{t}}$ is the energy required to bring the oxidant and reductant into a proper configuration in which they are separated by the required distance for electron transfer.

$\Delta G_{\mathrm{i}}$ is energy required for bond compression and stretching to achieve orbital's of equal energy and $\Delta G_{0}$ is the energy needed for solvent reorganization outside the coordination sphere.

$\mathrm{pH}$ influences the reaction in many ways a very low $\mathrm{pH}(0.14)$ is not appropriate for complexation of phen with cobalt(II) and iron(II), a higher pH (3.92) unfavours stability of cobalt(II) phen complex. At a much higher $\mathrm{pH}$ (5.0), the cerium(IV) and iron(III) begin to precipitate giving a suspension. Thus a $\mathrm{pH}$ range of 1-2 was found to be the optimum for titration as it represents a compromise of different $\mathrm{pH}$ based factors.

\section{Interferences Due to Other Metal Ions and Common Anions}

The effect of diverse metal ions/salts on the potentiometric estimation of iron(II) and iron(III) at $\mathrm{L} / \mathrm{M}$ ratio $=$ 14.28 was observed. The metal ions studied were grouped into three classes: $i$ ) non coordinating/non redox $\left(\mathrm{Na}^{+}, \mathrm{K}^{+}, \mathrm{Mg}^{2+}\right)$ ii) coordinating/non redox $\left(\mathrm{Ca}^{2+}\right.$, $\left.\mathrm{Zn}^{2+}, \mathrm{Pb}^{2+}, \mathrm{Al}^{3+}\right)$ iii) coordinating/redox $\left(\mathrm{V}^{4+}, \mathrm{V}^{5+}, \mathrm{Mn}^{2+}\right.$, $\left.\mathrm{Cu}^{2+}, \mathrm{Ni}^{2+}\right)$. Among the different metal ions studied, only vanadium(IV) and vanadium(V) had a strong interfering effect. Commonly present anions like chloride, sulphate, nitrate are poorly coordinating and redox inactive under experimental conditions, however phosphate, 
Table 2. Effect of other ions and compounds on potentiometric estimation of $3 \times 10^{-4} \mathrm{~mol} \mathrm{~L}^{-1}$ iron(II) and $2 \times 10^{-3} \mathrm{~mol} \mathrm{~L}{ }^{-1}$ iron(III) with cobalt(II) in presence of $2 \times 10^{-2} \mathrm{~mol} \mathrm{~L}^{-1}$ phen

\begin{tabular}{cccccccc}
\hline \multicolumn{2}{c}{ metal salt added, } & \multicolumn{2}{c}{$10^{3} c$ (found) $/$ mol L } & \multicolumn{2}{c}{$10^{3} c$ (added) $/$ mol L } & \multicolumn{2}{c}{ Recovery / \% } \\
$10^{3} c$ (salt) $/$ mol L & Iron(II) & Iron(III) & Iron(II) & Iron(III) & Iron(II) & Iron(III) \\
\hline $\mathrm{NaCl}$ & 2.00 & 0.40 & 0.40 & 0.40 & 0.40 & 100 & 100 \\
$\mathrm{KNO}_{3}$ & 2.00 & 0.40 & 0.40 & 0.40 & 0.40 & 100 & 100 \\
$\mathrm{MgSO}_{4}$ & 2.00 & 0.39 & 0.40 & 0.40 & 0.40 & 98 & 100 \\
$\mathrm{CaCl}_{2}$ & 0.02 & 0.39 & 0.40 & 0.40 & 0.40 & 98 & 100 \\
$\mathrm{ZnSO}_{4}$ & 0.02 & 0.39 & 0.38 & 0.40 & 0.40 & 99 & 97 \\
$\mathrm{PbNO}_{3}$ & 0.02 & 0.39 & 0.40 & 0.40 & 0.40 & 98 & 101 \\
$\mathrm{Al}_{2}\left(\mathrm{SO}_{4}\right)_{3}$ & 0.02 & 0.39 & 0.39 & 0.40 & 0.40 & 99 & 99 \\
$\mathrm{MnSO}_{4}$ & 0.02 & 0.39 & 0.39 & 0.40 & 0.40 & 98 & 98 \\
$\mathrm{CuCl}_{2}$ & 0.02 & 0.39 & 0.40 & 0.40 & 0.40 & 99 & 101 \\
$\mathrm{NiCl}_{2}$ & 0.02 & 0.39 & 0.40 & 0.40 & 0.40 & 98 & 102 \\
$\mathrm{VOSO}_{4}$ & 0.02 & 0.21 & 0.60 & 0.40 & 0.40 & 54 & 150 \\
$\mathrm{~V}_{2} \mathrm{O}_{5}$ & 0.02 & 0.39 & 0.56 & 0.40 & 0.40 & 98 & 140 \\
$\mathrm{NaH}_{2} \mathrm{PO}_{4}$ & 1.00 & 0.38 & 0.32 & 0.40 & 0.40 & 95 & 80 \\
$\mathrm{Na}_{4} \mathrm{P}_{2} \mathrm{O}_{7}$ & 1.00 & 0.38 & 0.30 & 0.40 & 0.40 & 95 & 75 \\
$\mathrm{Na}_{2} \mathrm{H}_{2} \mathrm{EDTA}$ & 0.10 & 0.34 & 0.10 & 0.40 & 0.40 & & 25 \\
\hline
\end{tabular}

diphosphate and EDTA which strongly bind iron(III) influence the analysis in the following order EDTA > diphosphate $>$ phosphate which strongly correlates with the strength with which these ions bind iron(III). The results are shown in Table 2.

\section{Application}

The proposed method was applied for simultaneous estimation of iron(II) and iron(III) in iron rich Dal Lake with the results summarized in Table 3. Dal Lake is the urban lake towards the NE of Srinagar city and is a tectonic lake at an altitude of about $1,584 \mathrm{~m}$ above sea level. The lake lies between $34^{\circ} 6^{\prime} \mathrm{N}$ and $34^{\circ} 10^{\prime} \mathrm{N}$ latitude and $74^{\circ} 50^{\prime} \mathrm{E}$ and $74^{\circ} 54^{\prime} \mathrm{E}$ longitude and covers an area of about $11.50 \mathrm{~km}^{2}$. The lake is divided into four basins: Hazratbal, Boddal, Nageen and Gagribal. Figure 3 Being an urban lake, the Dal is surrounded by developed land; most of the lakeshore is occupied by houses, hotels, restaurants and houseboats. The Gagribal and Hazratbal basins lie in the vicinity of maximum habita- tion including hotels, restaurants and houseboats. Since there is no industrial or mining activity prevalent in the area, therefore point source input of domestic wastes and urban runoff are major contributors of elevated concentration of iron species in these two basins relative to the Boddal and Nageen basins. The results obtained by the proposed potentiometry were in good agreement with those obtained by standard spectrophotometry.

The method is based on green electrochemistry approach and represents environmentally benign simultaneous estimation of iron oxidation states. The novelties of this method include: $i$ ) simple one titration step procedure ii) low cost and energy, iii) non-carcinogenic and toxic chemicals $i v$ ) low and nonhazardous solid waste $v$ ) more atom-economical and robust, vi) better waste management by safe disposal of solid waste ${ }^{27}$ (The reaction mixture along with other unused solutions when mixed together and made alkaline forms a solid waste of metal hydroxides which can be dumped safely preventing risk of human exposure, and damage to aquatic environment).

Table 3. Comparative iron speciation analysis of four basins of Dal lake, Hazratbal, Boddal, Nageen and Gagribal

\begin{tabular}{|c|c|c|c|c|c|c|}
\hline \multirow[t]{2}{*}{ Basin } & \multicolumn{3}{|c|}{$\begin{array}{l}\text { Proposed potentiometry } \\
\qquad 10^{6} \mathrm{c} / \mathrm{mol} \mathrm{L}^{-1}\end{array}$} & \multicolumn{3}{|c|}{$\begin{array}{l}\text { Spectrophotometry }^{(\mathrm{a})} \\
10^{6} \mathrm{c} / \mathrm{mol} \mathrm{L}^{-1}\end{array}$} \\
\hline & $\mathrm{Fe}(\mathrm{II})^{(\mathrm{b})}$ & $\mathrm{Fe}(\mathrm{III})$ & Total & $\mathrm{Fe}(\mathrm{II})^{(\mathrm{b})}$ & $\mathrm{Fe}(\mathrm{III})$ & Total \\
\hline Boddal & 5.2 & 30 & 35.2 & 5.2 & 32 & 37.2 \\
\hline Hazratbl & 9.0 & 52 & 61.0 & 9.3 & 55 & 64.3 \\
\hline Nageen & 3.9 & 30 & 33.9 & 4.1 & 32 & 36.1 \\
\hline Gagribal & 9.0 & 63 & 72.0 & 9.5 & 66 & 75.5 \\
\hline
\end{tabular}

(a) Using 1,10-phenanthroline method.

(b) Simple evaporation was used for 20-times pre-concentration. 


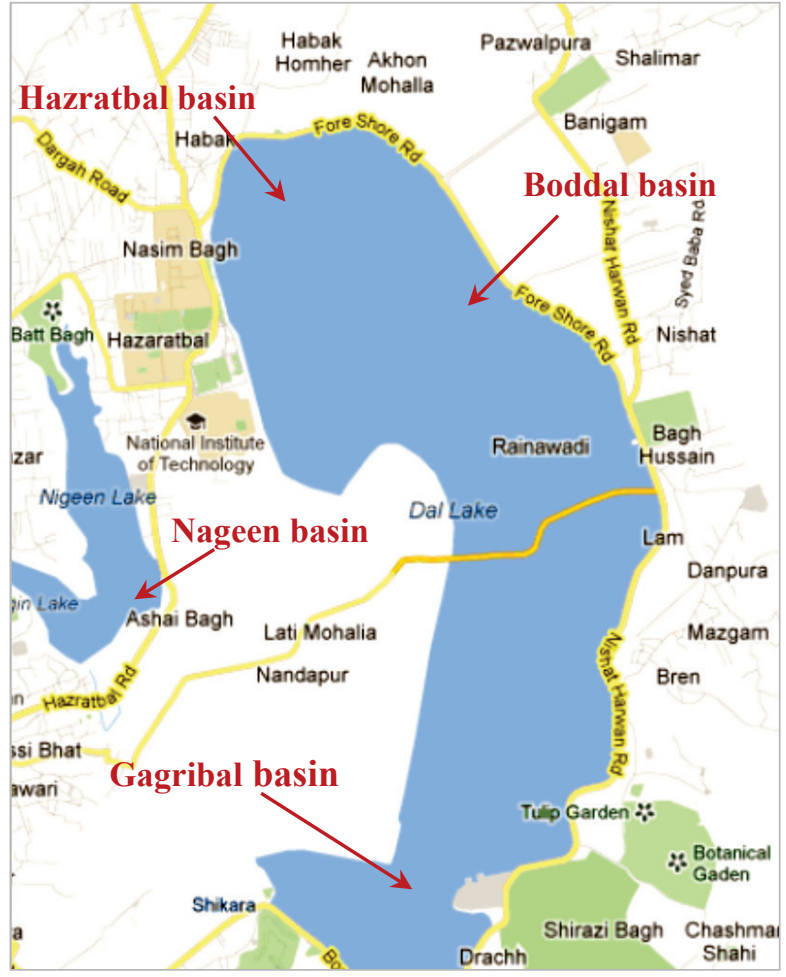

Figure 3. Geographical location map of Dal lake showing four basins.

\section{CONCLUSION}

This work describes the environment friendly method for speciation of iron(II) and iron(III) through simultaneous potentiometric titration involving simple one step procedure and non-toxic chemicals. The method is based on 1,10-phenanthroline ligand modified electrochemical behavior and aims at green electro-analytical chemistry. A theoretical model to explain phen modified electrochemical behavior was provided. The method has been applied with good results to the iron speciation analysis in synthetic and natural water samples from world famous Dal Lake.

Acknowledgements. M. A Rizvi wishes to dedicate this article to the loving memories of Mohammad Afaq, the inspiring teacher.

\section{REFERENCES}

1. T. M. Florence, Talanta 29 (1982) 345-355.

2. E. Nakayama, V. Suzuki, K. Fujiwara, and Y.Kitano, Anal. Sci. 5 (1989) 129-139.

3. M. D. Luque Castro and M. V. Cases, Analyst 109 (1984) 413 419.

4. M. A. Anderson and F. M. Morel, Limnol. Oceanogr. 27 (1982) 789-813.

5. H. Hong and D. R. Kester, Limnol. Oceanogr. 31 (1986) 512-524.

6. Y. Kanai, Analyst 115 (1990) 809-812.

7. F. J. Szydlowski, D. L. Dunmire, E. E. Peck, R. L. Eggers, and W. R. Matson, Anal. Chem. 53 (1981) 193-196.

8. K. W. Bruland and E. L. Rue, "The biogeochemistry of iron in seawater, IUPAC series on analytical and physical chemistry of environmental systems", Wiley Chichester: West Sussex, UK, 2001; pp. 255-275.

9. P. Praus and M. Blahutova, Fresenius J. Anal. Chem. 369 (2001) 466-468.

10. Y. Takagai and S. Igarashi, Anal. Sci. 19 (2003) 1207-1209.

11. N. A. Zatar, A.Z. Abu-zuhri, M. A. Al-nuri, F. M. Mahmoud, and A. A. Abu-Obaid, Spectrosc. Lett. 22(1989) 1203-1214.

12. S. Oszwaldowski and A. Pikus, Talanta 58 (2002) 773-783.

13. A. B. Tabrizi, J. Hazard. Mater. 183 (2010) 688-693.

14. N. Teshima, H. Katsumata, and T. Kawashima, Anal. Sci. 16 (2000) 901-911.

15. M. A. Rizvi, R. Maqsood, and B. U. Khan, J. Chem. Educ. 88 (2011) 220-222.

16. M. A. Rizvi, R. Maqsood, R. Jan, and G. M Peerzada Chem. Educator 16 (2011) 72-75.

17. M. A. Rizvi, N. Teshima, and G. M. Peerzada, Asian J. of Chem. 25(9) (2013) 4776-4778.

18. S. Raashid, M. A. Rizvi, and B. U. Khan, Journal of Pharmacy Research 5(5) (2012) 2715-2720.

19. R. L. David "Handbook of Chemistry and Physics, $86^{\text {th }}$ edn", CRC press Taylor \& Francis, New York, 2005-2006; pp. 8-21.

20. R. J. P. Williams, J. Chem. Soc. 0 (1955) 137-145.

21. B. M. Gordon, L. L. Williams, and N. Sutin, J. Am. Chem. Soc. 83 (1961) 2061-2064

22. W. A. E. McBryde "A critical review of equilibrium data for proton and metal complexes of 1,10-phenanthroline, 2,2bipyridyl and related compounds", Pergamon, Oxford 1975.

23. K. Ogura, H. Urabe, and T.Yosino, Electrochim. Acta 22 (1977) 285-287.

24. K. Ogura and K. Miyamoto, Electrochim. Acta 22 (1977) 1357 1359.

25. W. Q. Huang, G.F.Huang, L. L. Wang, and X. G. Shi, Int. J. Electrochem. Sci. 3 (2008) 1316-1324.

26. J. E. Huheey, A. E. Keiter, R. L. Keiter, "Inorganic Chemistry Principles of structure and Reactivity $4^{\text {th }}$ Edn" Pearson Education 2003 pp. 558-560.

27. R. B. Pojasek, "Using solidification as a waste detoxification process" Ann Arbor Science, Michigan, 1982, Ch.11. 